\title{
Дыхание почв как индикатор токсичности технозёмов
}

\author{
Слуковская М.В. ${ }^{1,2}$, Долгих А.В. ${ }^{3}$, Новиков А.И. ${ }^{1}$, Мосендз И.А. ${ }^{2}$, Кременецкая И.П. ${ }^{1}$ \\ ${ }^{1}$ Институт химии и технологии редких элементов и минерального сырья им. И.В. Тананаева КНЦ \\ PAH, Anamumbl,slukovskaya.mv@gmail.com \\ 2 Лаборатория природоподобных технологий и техносферной безопасности Арктики КНЦ РАН, \\ Anamumbl \\ ${ }^{3}$ Институт географии РАН, Москва, dolgikh@igras.ru
}

\begin{abstract}
Аннотация. Исследованы свойства технозёмов, созданных с применением различных видов горнопромышленных отходов на участках техногенного ландшафта с высоким уровнем загрязнения тяжелыми металлами в условиях Субарктики. Проанализированы данные о содержании водорастворимых и обменных форм меди, никеля, кальция и магния в технозёмах и исходной почве, рассчитаны модули токсичности как соотношение между суммой никеля и меди к сумме кальция и магния. Установлена взаимосвязь между модулем токсичности почв и эмиссией ими диоксида углерода. Показано, что основным фактором, влияющим на экологическое состояние почв, является высокая токсичность. В то же время, выявлено влияние влажности субстратов на почвенное дыхание, что указывает на необходимость учитывать влагоёмкость материалов при конструировании технозёмов.
\end{abstract}

Ключевые слова: эмиссии диоксида углерода; медь; никель; горнопромышленные отходы; Субарктика; макроэлементы; тяжелые металлы; фракционирование тяжелых металлов.

\section{Soil respiration as an indicator of the technosol toxicity}

\author{
Slukovskaya M.V. ${ }^{1,2}$, Dolgikh A.V. ${ }^{3}$, Novikov A.I. ${ }^{1}$, Mosendz I.A. ${ }^{2}$, Kremenetskaya I.P. ${ }^{1}$ \\ ${ }^{1}$ I.V. Tananaev Institute of Chemistry and Technology of Rare Elements and Mineral Raw Materials KSC \\ RAS, Apatity,slukovskaya.mv@gmail.com \\ ${ }^{2}$ Laboratory of Nature-Inspired Technologies and Environmental Safety of the Arctic \\ ${ }^{3}$ Institute of geography RAS, Moscow,dolgikh@igras.ru
}

\begin{abstract}
The properties of technosols created using alkaline mining wastes in the area with a high level of trace metals contamination in the Subarctic are investigated. Data on the content of water-soluble and exchangeable forms of copper, nickel, calcium and magnesium in technosols and initial soil have been analyzed, toxicity criteria as the ratio between the sum of nickel and copper to the sum of calcium and magnesium have been calculated. The relationship between the toxicity criteria and the emission of carbon dioxide of soils has been established. It is shown that the main factor affecting the soil respiration is high toxicity. At the same time, the effect of substrate moisture on soil respiration has been revealed, which indicates the need to take into account the moisture capacity of materials in the design of technosols.

Key words: carbon dioxide emission; copper; nickel; mining waste; Subarctic; macronutrients; heavy metals; fractionation of heavy metals.

\section{Введение}

Арктические ландшафты - уникальный природный ресурс, выполняющий важнейшие экологические функции и экосистемные сервисы, включая сохранение биоразнообразия, депонирование углерода и влияние на климат. Исследование геохимических свойств материалов, которые могут быть использованы в технологиях уменьшения накопленного экологического ущерба в Арктической зоне РФ (загрязнение почв тяжелыми металлами, деградация и эрозия почв, изменение гидрологического режима и углеродного баланса территорий, формирование отвалов горноперерабатывающих предприятий) и разработка способов, обеспечивающих реабилитацию и устойчивость почвенно-растительных комплексов на деградированных территориях, является важной научной задачей, имеющей как фундаментальный, так и практический аспект.

В настоящей работе представлены результаты полевого эксперимента, который выполняется в зоне воздействия АО «Кольская ГМК» (г. Мончегорск). Атмосферные выбросы предприятия
\end{abstract}


привели к накоплению никеля и меди в почве, деградации и исчезновению леса, изменению циклов углерода и азота, эрозии почвы и формированию техногенной пустоши (Евдокимова и др., 2011; Кашулина и др., 2015; Лянгузова и др., 2015; Manninen et al., 2015; Кашулина, 2017).

\section{Район проведения исследования и схема эксперимента}

Полевой эксперимент по ремедиации почвы с использованием горнопромышленных отходов был заложен в 2010-2013 гг. на двух участках в импактной зоне предприятия. Почвы участков являются наиболее распространенными в регионе исследования: участок 1 - хемозём по абрадированному подзолу (67.940050, 32.838117), участок 2 - торфяная почва без растительности (67.929761, 32.858956).

Технология ремедиации предполагает создание почвенной конструкции (технозёма) с использованием горнопромышленных отходов (слой 1 , толщина -5 см), вспученного вермикулита (слой 2, толщина - 1 см) и семян четырёх видов злаков. Для создания слоя 1, нанесенного на поверхность деградированной почвы, были использованы такие горнопромышленные отходы, как серпентинитомагнезит (CM), карбонатитовые отходы (КО), и серпентиновые отходы (CO) а также песок (П) в качестве субстрата сравнения. Цель исследования - оценка влияния токсичности почвеннорастительных конструкций на дыхание технозёмов.

Отбор почв (слой 0-5 см) и измерения эмиссии $\mathrm{CO}_{2}$ проводился в вегетационный сезон 2018 г. Измерение эмиссии диоксида углерода проводилось методом закрытых камер с использованием системы на основе газоанализатора AZ-7752 (AZ-Instruments, КНР) (Карелин и др., 2015). Водорастворимые формы определялись в водной вытяжке, обменные - в аммонийно-ацетатном буферном растворе (ААБ), рН 4.65 (Ладонин, 2006; Минкина и др., 2008; Сиромля, 2009). Для торфяных высокозагрязнённых почв применялась трёхкратная обработка почвы ААБ (Слуковская и др., 2018). Полученные растворы анализировали с помощью масс-спектрометра с индуктивно связанной плазмой ELAN 9000 DRC-e (Perkin Elmer, СШA).

\section{Результаты и обсуждение}

Горнопромышленные отходы содержат высокие концентрации карбонатов и силикатов кальция и магния и являются основной корнеобитаемой средой для злаков. Известно, что ионы Са ${ }^{2+}$ и $\mathrm{Mg}^{2+}$ могут конкурировать $\mathrm{Cu}^{2+}$ и $\mathrm{Ni}^{2+}$ и обеспечивать защитный эффект для живых организмов

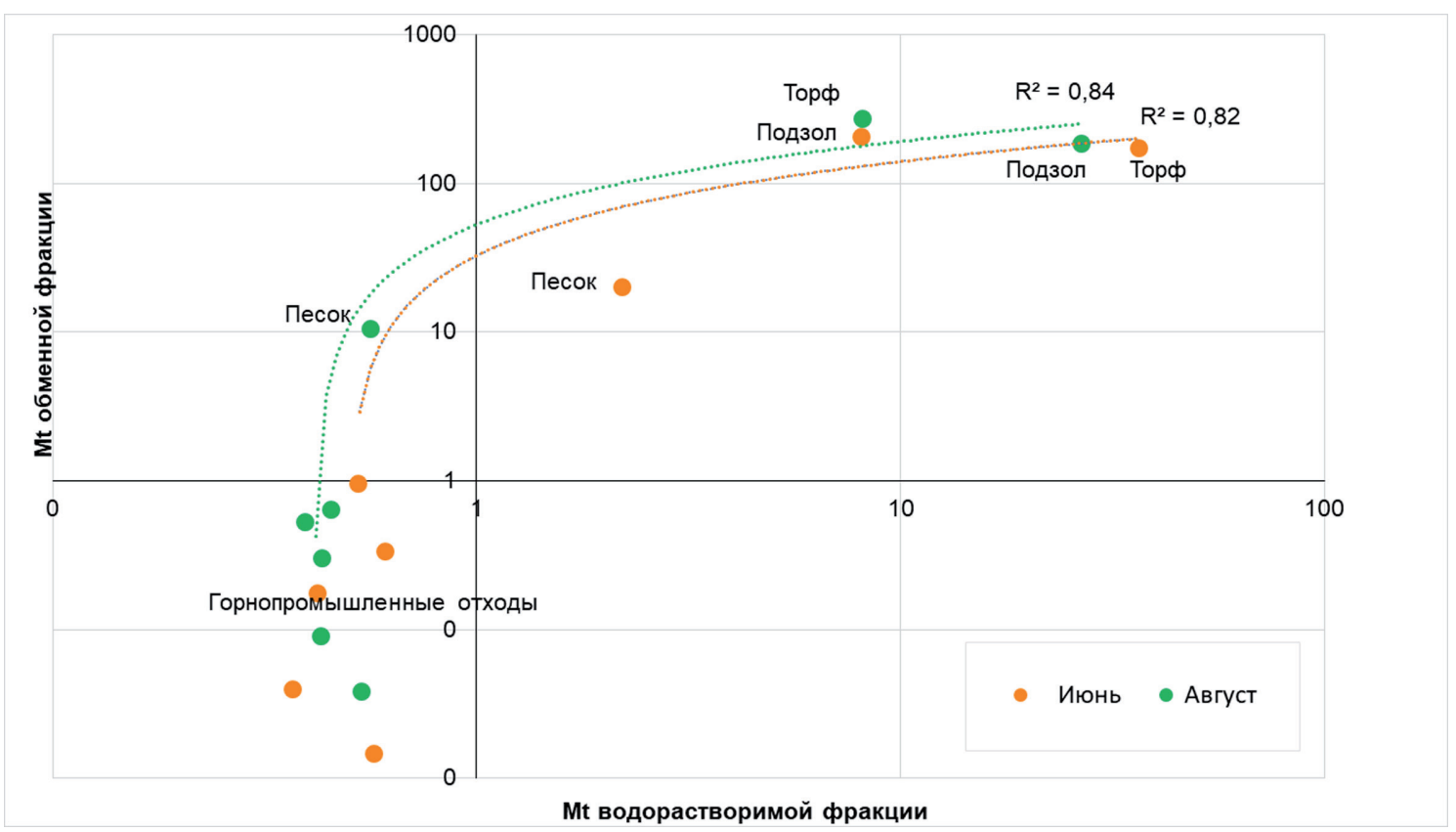

Рис. 1. Модуль токсичности почв и технозёмов, слой 0-5 см.

Fig. 1. The module of soil and technosol toxicity, a layer of 0-5 cm. 


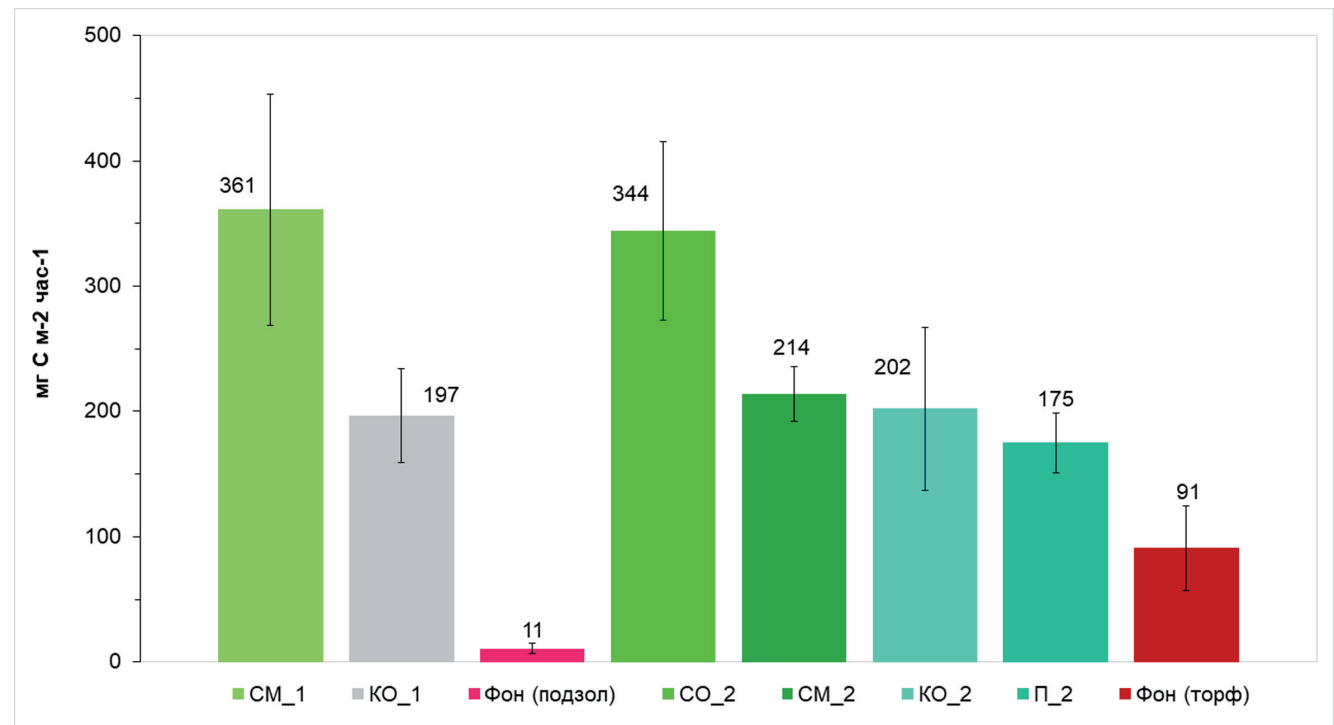

Рис. 2. Почвенная эмиссия диоксида углерода. Fig. 2. Carbon dioxide soil emission.

(Thakali et al., 2006; Antunes et al., 2007). В частности, результаты многих исследований показывают, что кальций и магний уменьшают токсичность металлов для растений (Kinraide et al., 2004; Lock et al., 2007; Luo et al., 2008; Wu \& Hendershot, 2010). Токсичность почвы и технозёма при мультиэлементном загрязнении тяжелыми металлами предложено оценивать с помощью критерия токсичности (Mt), основанного на мольном соотношении тяжелых металлов к макроэлементам (Евдокимова и др., 2011; Slukovskaya et al., 2017):

$$
\mathrm{Mt}=\left(v_{\mathrm{Ni}}+v_{\mathrm{Cu}}\right) \times 100 /\left(v_{\mathrm{Ca}}+v_{\mathrm{Mg}}\right) .
$$

Существует высокая степень корреляции между критерием токсичности водорастворимой и обменной фракций $\left(\mathrm{R}^{2}=0.7\right)$, причем логарифмическая кривая наилучшим образом описывает это соотношение (рис. 1).

Модуль токсичности водорастворимой фракции слабо коррелирует между началом и концом вегетационного периода $\left(\mathrm{R}^{2}=0.35\right)$, а Мt обменной фракции - сильно $\left(\mathrm{R}^{2}=0.95\right)$, что можно объяснить высокой мобильностью элементов в водорастворимой форме (Сиромля, 2009). Максимальные значения модуля токсичности $(\mathrm{Mt}=172-272)$ соответствуют контрольным почвам обоих участков. Песчаный технозём имел значения $\mathrm{Mt}=0.6-2.2$ для водорастворимых фракций и $\mathrm{Mt}=10.5-20.0$ для обменных фракций.

Модуль токсичности обеих фракций для всех технозёмов из горнопромышленных отходов имел значения меньше единицы. Ранее показано, что при значениях критерия токсичности больше 1 происходит ингибирование ростовых процессов и фотосинтетической активности злаковых растений (Слуковская и др., 2017; Slukovskaya et al., 2017).

Наименьшие значения эмиссии диоксида углерода отмечены для фонового хемозёма по подзолу участка $1(9 \pm 4$ мг С/м².час при средней влажности $15 \%)$ и торфяной фоновой почвы без растительности участка $2(77 \pm 29$ мг С/м².час при влажности $42 \%)$. Среди технозёмов наименьшие значения эмиссии соответствовали варианту с песком (150 \pm 20 мг $\mathrm{C} / \mathrm{M}^{2} \cdot$ час, влажность $\left.47 \%\right)$. Значения дыхания почвы для технозёмов с использованием горнопромышленных отходов составляли 178-319 мг С/м².час (рис. 2).

Дыхание почвы имело высокий уровень отрицательной корреляции с модулем токсичности, причем коэффициент корреляции с Mt обменной фракции составлял 0.74-0.82, a с корреляция с Mt водорастворимой фракции был немного ниже, коэффициент корреляции составлял 0.52-0.76.

Существенная разница в дыхании почвы между вариантами СМ и КО участка 1 может быть обусловлена более высокой влажностью СМ (17 \%) по сравнению с КО (9 \%). Влажность технозёмов на участке 2 составляла $22 \%$ для КО, 27\% для СО и $39 \%$ для СМ. 
Таким образом, основным лимитирующим фактором эмиссии диоксида углерода является токсичность почвы или технозёма (Mt>1), а второстепенным (при отсутствии токсичности) - влажность субстрата, что характерно и для природных криогенных экосистем (Карелин и др., 2015).

\section{Заключение}

Впервые проведено изучение эмиссии диоксида углерода на участках ремедиации техногенной пустоши с помощью горнопромышленных отходов и ее связи с комплексным показателем токсичности почвы, включающим подвижные формы поллютантов и макроэлементов. Показано, что ингибирование почвенного дыхания происходит при значениях данного показателя меньше 1 , что полностью соответствует полученным ранее данным для биометрических и физиологических параметров злаковых растений.

Критерии токсичности, рассчитанные на основе содержания водорастворимых и обменных форм элементов, были существенно связаны между собой и проявляли схожие закономерности по влиянию на почвенное дыхание. Наиболее тесная взаимосвязь наблюдается между почвенным дыханием и содержанием элементов в обменной фракции.

При отсутствии токсического действия тяжелых металлов (модуле токсичности менее 1) фактором, оказывающим влияние на эмиссию диоксида углерода, является влажность почвы или технозёма. Таким образом, при выборе материалов для ремедиации и создания корнеобитаемого слоя, необходимо учитывать показатели их влагоемкости и гранулометрического состава для обеспечения оптимального функционирования экосистемы.

Работа выполнена при поддержке РФФИ 16-35-60022, полевые измерения эмиссии диоксида углерода выполнены в рамках темы ГЗ № 0148-2019-0006.

\section{Литература}

1. Ладонин Д.В. Формы соединений тяжелых металлов в техногенно-загрязненных почвах. Автореф. докт. биол. наук. Москва. 2016. 42 с.

2. Карелин Д.В., Замолодчиков Д.Г., Краев Г.Н. Методическое руководство по анализу эмиссий углерода из почв поселений в тундре. М. Изд-во: ЦЭПЛ РАН. 2015. 64 с.

3. Карелин Д.В., Замолодчиков Д.Г., Зукерт Н.В., Честных О.В., Почикалов А.В., Краев Г.Н. Межгодовые изменения ФАР и влажности почвы в теплый сезон могут быть важнее для направления годового углеродного баланса в тундрах, чем колебания температуры. Журнал общей биологии. 2013. Т. 74. № 1. С. 3-22.

4. Минкина Т.М., Мотузова Г.В., Назаренко О.Г., Крыщенко В.С., Манджиева С.С. Комбинированный прием фракционирования соединений металлов в почве. Почвоведение. 2008. № 11. С. 1324-1333.

5. Сиромля Т.И. К вопросу о подвижных формах соединений химических элементов в почвах. Сибирский экологический журнал. 2009. № 2. С. 307-318.

6. Слуковская М.В., Кременецкая И.П., Дрогобужская С.В., Новиков А.И. Модификация метода последовательного экстрагирования для анализа высокозагрязненной торфяной почвы Мончегорской техногенной пустоши. Материалы Всероссийской научной конференции «Химическое и биологическое загрязнение почв». Товарищество научных изданий КМК. Пущино. 2018. С. 253-256.

7. Antunes, P.M.C., Hale, B.A., Ryan, A.C., 2007. Toxicity versus accumulation for barley plants exposed to copper in the presence of metal buffers: progress towards development of a terrestrial biotic ligand model. Environ. Toxicol. Chem. V. 26. P. 2282-2289.

8. Kinraide, T.B., Pedler, J.F., Parker, D.R., 2004. Relative effectiveness of calcium and magnesium in the alleviation of rhizotoxicity in wheat induced by copper, zinc, aluminum, sodium, and low pH. Plant Soil 259. P. 201-208.

9. Lock, K., Criel, P., De Schamphelaere, K.A.C., Van Eeckhout, H., Janssen, C.R., 2007. Influence of calcium, magnesium, sodium, potassium and $\mathrm{pH}$ on copper toxicity to barley (Hordeum vulgare). Ecotoxicol. Environ. Saf. V. 68. P. 299-304.

10. Luo, X.S., Li, L.Z., Zhou, D.M., 2008. Effect of cations on copper toxicity to wheat root: implications for the biotic ligand model. Chemosphere. V. 73. P. 401-406.

11. Slukovskaya M.V., Kremenetskaya I.P., Ivanova L.A., Vasilieva T.N. Remediation in conditions of an operating copper-nickel plant: results of perennial experiment. Non-ferrous Metals. 2017. V. 2. P. $20-26$.

12. Слуковская М.В., Новичонок Е.В., Кременецкая И.П., Мосендз И.А., Дрогобужская С.В., Марковская Е.Ф. Применение Festuca rubra L. в фиторемедиации: комплексная оценка влияния техногенного грунта на растение. Ученые записки Петрозаводского государственного университета. 2017. № 4 (165). С. $70-80$. 
13. Slukovskaya M.V., Ivanova L.A., Kremenetskaya I.P., Gorbacheva T.T., Drogobuzhskaya S.V., Lashchuk V.V., Markovskaya E.F. Rehabilitation of industrial barren in arctic region using mining wastes. The Open Ecology Journal. 2018. V. 11. P. 1-13.

14. Slukovskaya, M.V.; Kremenetskaya, I.P.; Drogobuzhskaya, S.V.; Ivanova, L.A.; Mosendz, I.A.; Novikov, A.I. Serpentine mining wastes - materials for soil rehabilitation in $\mathrm{Cu}-\mathrm{Ni}$ polluted wastelands. Soil Science. 2018. V. 183 (4). P. 141-149.

15. Thakali, S., Allen, H., Di Toro, D., Ponizovsky, A., Rooney, C., Zhao, F., McGrath, S., A terrestrial biotic ligand model. 1. Development and application to $\mathrm{Cu}$ and $\mathrm{Ni}$ toxicities to barley root elongation in soils. Environ. Sci. Technol. 2006. V. 40. P. 7085-7093.

16. $\mathrm{Wu}, \mathrm{Y} . \mathrm{H} .$, Hendershot, W.H. Effect of calcium and $\mathrm{pH}$ on copper binding and rhizotoxicity to pea (pisum sativum L.) root: empirical relationships and modeling. Arch. Environ. Contam. Toxicol. 2010. V. 59. P. 109-119. 